carbon dioxide, which was the immediate inspiration for her subsequent investigations.

The introductory part of the volume gives a brief history of Chladni's life, publications and work, a summary of subsequent theoretical developments, concluding by a description of the author's metbod of using carbon dioxide as a means of exciting vibrations. The main section of the book consists of 47 full-page plates with their accompanying texts. These plates reveal the wonderful variety of complex but symmetrical patterns which can be generated by vibrating plates. Part 1 of this section is headed "Symmetry", Part 2 "Repeating Nodal Figures: Designs", and Part 3 "Powders and Vibrating Plates". The beautiful and often decorative designs which are produced by Dr. Waller's techniques must be seen to be believed, and her descriptions of methods of producing them and her explanations are equally fascinating.

The book is profusely illustrated-in fact, she herself refers to it as 'a picture book'-and contains a large number of references to original publications and books covering the period from Chladni's day to the present time.

I have referred to this work of Mary Waller's as exceptional, as indeed it is. As a purely scientific book it indicates in many ways how she has advanced our knowledge of the vibrations of plates. From an engineering aspect such work in its application has great importance. Designers cannot fail to be impressed by the numerous fascinating and unusual patterns illustrated. Such beautiful patterns and the techniques which produce them so easily have been admired by all who have been privileged to see them.

Perhaps the book should be primarily regarded as a scientific book (free from mathematics), of interest to physicists and engineers alike, but it must also interest a much wider field of readers, designers, and also those who like a good book of pictures.

The publishers also deserve praise for the excellent quality of the reproductions of the vibration patterns, which adds in no small measure to the value of the book.

A. B. Woon

\section{BASIC CHEMISTRY?}

Advances in Chemical Physics

Vol. 3. Edited by I. Prigogine. Pp. ix +372 . (Now York: Interscience Publishers, Inc.; London: Interscience Publishers, Ltd., 1961.) 87s.

TT could be argued that physical chemistry as a 1 separate intellectual discipline has a completed history. It began in 1887 with the foundation of the Zeitschrift für physikalische Chemie and ended in 1927 with the publication of Heitler and London's paper on the hydrogen molecule in the Zeitschrift für Physik. Physical chemistry had become chemical physics. By chemical physics we now generally understand the attempt to deal with problems of chemical interest in terms of the relevant basic physics, usually quantum mechanics, thermodynamics or statistical mechanics. Such problems include chemical kinetics, molecular structure and transport processes. This does not moan, however, that chemistry has been handed over to the physicists. On the contrary, almost all the contributors to the present volume write from laboratories of physical chemistry, theoretical chemistry, or just plain chemistry.
The range of subject-matter and of difficulty here is wide. For example, the article on electron diffraction and molecular structure, by Bastiansen and Skancke, is a very clear general account of the position which could usefully be read by a finalyear chemistry student. So is that on the mechan. isms of organic electrode reactions by Elving and Pullman. Some of the articles, on the other hand, are much more difficult.

The important account of the theory of propagation of flames and detonations by Hirschfelder and Curtiss, for example, would be heavy going for, and might even mislead, a reader not acquainted with the field. The habit of grouping factors together as dimensionless parameters, without much discussion of their physical meaning, and referring to the parameter only by its symbol thereafter, makes for conciseness but is daunting to the less assiduous seeker after information. Again, the remark at the end of the article: "... there is no case where the experimental detonation velocity corresponds to a detonation ending precisely at the Chapman-Jouguet point". though strict]y true, takes on a different shade of meaning if one knows that the discrepancy is about $\frac{1}{2}$ per cent. For those prepared to study it, however, this 70-page review of the important recent theoretical work of Hirschfelder's group is the highlight of the volume.

Another contribution requiring, and worthy of, careful study is Johnston's article on quantum mechanical tunnelling and chemical reaction-rates. The remaining articles are on powder electrodes (Tomassi), diamagnetism (Pacault, Hoarau, and Marchand), and two contributions to the thermodynamics of irreversible processes. One of these, by Bak, considers non-linear problems, including the possibility of oscillating reactions, and the other, by Ono, deals with variational principles.

This is clearly a volume with something to interest most physical chemists, and even some physicists.

\section{T. L. CotTrelL}

\section{SEPARATING ISOTOPES}

\section{Separation of Isotopes}

Edited by Dr. H. London. Pp. xvi $+488+16$ plates. (London: George Newnes, Ltd., 1961.) 80s. net.

7 HIS volume, which is one of Newnes's Nuclear Books, has been prepared by sixteen contributors writing from Great Britain (9), Germany (3), France (2), the United States (1) and Australia (1). The book treats the subject at a highly technical level and has obviously been written for the use of a postgraduate worker with considerable knowledge of the subject. For example, no table of naturally occurring isotopes with their abundances is given although most of the book is concerned with the separation of individual isotopes from naturally occurring mixtures. The approach is mainly physico-chemical and the treatment is theoretical, although some chemical engineering details are provided, including flow-sheets and costs. Separation processes discussed range from those used on a large scale (for example, diffusion and distillation) to those used for preparing small quantities (such as electromagnetic separation), from those conceived and tried (biological methods, etc.) to those conceived and untried (for example, use of hyperfine splitting of electronic states). 